IMAGINATION, COGNITION AND PERSONALITY, Vol. 20(4) 315-346, 2000-2001

\title{
AN ETHNOGRAPHIC STUDY OF FORMER DISSOCIATIVE IDENTITY DISORDER PATIENTS
}

\author{
ELI SOMER \\ University of Haifa, Israel and \\ Maytal_Israel Institute for Treatment and Study of Stress, Haifa
}

ORIT NAVE

Ofek—Center for Psychological Services, Herzliya, Israel

\begin{abstract}
Three therapists interviewed five of their former DID patients in a semistructured depth interview. Two respondents were Israeli, two were North American, and one was Dutch. Prior to therapy their sense of self had been vague at best and was described as an uncomfortable feeling of internal void. They all had at least rudimentary recollections of their childhood suffering. They were more likely to believe their memories of childhood abuse if they succeeded in experiencing the feelings connected with those images. Fantasy, spirituality, and religion played a role in helping them manage their existence. Their integration process was incremental, as they gradually embraced the disowned aspects and functions of the self. Dissociative and ego state processes were still present during the period of data collection. The results are discussed in terms of the convergence of borderline and dissociative symptomatology, the role of fantasy and spirituality in DID, therapeutic processes, and patterns of treatment outcome.
\end{abstract}

Most of the descriptive literature on Dissociative Identity Disorder (DID) has been presented from the clinical investigators' perspectives and is comprised either of case studies or quantitative research reports. Mental health scholars who try to describe clinical phenomena in the scientific literature face a significant challenge in adopting contemporary critical thinking without losing the human being in the process. In this light is it noteworthy that qualitative studies about the essence 
of the multiplicity experience have been conspicuously absent from scientific writings. Self-plurality has been widely explored from various "objective" perspectives, yet our understanding of these occurrences will remain limited without a more thorough exploration of the phenomena from the perspective of the subjects' own experiences. From an existential-phenomenological perspective, experiences are considered to be the very grounds from which all other knowledge emerges [1].

Several DID clinicians attempted to include the patients' perspective by writing their scholarly ventures jointly with a former patient [e.g., 2, 3]. These publications steered away from the phenomenology of DID and thus could not capture the flavor of the experience. A few biographical novels have been written by former DID patients [e.g., 4, 5], or from a joint therapist-patient perspective [e.g., 6]. However, only two studies have examined the dissociative experience from the patient's perspective: one described a controlled qualitative analysis of early diaries of DID patients [7] and the other uncovered the subjective post-hoc meanings given by a former DID patient to her artwork [8]. The purpose of the current study is to present a systematic exploration of subjective perspectives on DID in order to introduce a better scholarly appreciation of the experience.

\section{METHOD}

This study was designed in the tradition of phenomenological inquiry [9]. In this kind of research, the investigators' subjective understanding of their participants' experiences become valuable tools in deciphering the meaning of specific circumstances in the lives of their subjects.

\section{Development of the Interview Guide}

Based on our initial understanding of the etiology and dynamics of pathological dissociation, and in consultation with several other trauma and dissociation clinicians in three different continents, we developed a list of relevant psychological processes we wanted to explore. From this we constructed an interview guide that included the following questions pertaining to experiences before, during, and after the therapy: What were your beliefs about yourself and the world you lived in? What was your sense of identity and how has it changed? What was your memory like during that time? What were your feelings about your diagnosis? What were the circumstances of your dissociative experiences and have they changed over time? What has your spiritual and fantasy life been like? What has your process of integration/healing been like?

\section{Procedure}

To maximize the respondents' sense of safety while minimizing interference in patient-therapist relationship, our research design required collaboration with therapists who were willing to interview their consenting former DID patients. The 
sample consisted of five former DID patients solicited from the practice of three clinicians specializing in the treatment of severe dissociative disorders. The whereabouts of six of their former patients were known and they were contacted. One former patient declined our invitation to participate. Two clinicians (the authors) were Israeli, one was Dutch. The clinicians approached their former DID patients and offered to meet with them in a non-billable follow-up research interview. The ethnographic research method is not aimed at producing representative data but rather at providing an in-depth description of a lived experience [10-12]. The subjects for this study were chosen from a fairly small population: former DID patients who are considered both by their therapists and by themselves to be healed. Sampling was therefore non-random and deliberate.

Two subjects were Israeli and were treated by the second author, a clinical psychologist. Two were North Americans temporarily residing in Israel and were treated by the first author, also a clinical psychologist. The fifth subject was Dutch and was treated in the Netherlands by a female clinical social worker. All subjects were interviewed at least one year following their final integration (range 1-3 years). Two were still seen for infrequent post-integration follow-up sessions. The Dutch interview was transcribed and translated into English by a bilingual Dutch psychologist.

Each respondent participated in a semi-structured in-depth interview that followed a pre-planned outline. All subjects but one were interviewed in face-to-face sessions that lasted three to four hours. Lorraine, who was abroad at the time the data were collected, was interviewed in writing during a prolonged electronic mail correspondence. The questions were sent to her one-by-one and were presented in the order maintained at the other interviews. Despite the impersonal mode of interviewing, her replies were thoughtful and were elaborate, demonstrating a keen motivation to explore the issues raised by the investigators. Her responses were followed by subsequent (e-mailed) investigator's questions, as had been the case in the other face-to-face interviews. Two former patients preferred that the interviewers not take notes during the sessions. For them the conversations were recorded and later transcribed. Notes were taken during the other three interviews. Each one of the content areas in the interview plan was investigated following the ethnographic interview model suggested by Spradley [10] and included descriptive, contrast, contextual, and taxonomic questions. All aspects of the study reported here are in compliance with American Psychological Association standards with regard to research and the treatment of study samples.

\section{Data Analysis}

The transcriptions were analyzed using a cross-case analysis that involved searching for cross-case references to the issues on our interview guide. We also looked for themes that were beyond our interview guide. In the first phase of data analysis all the interviews were repeatedly read and reread until we reached a level 
of familiarity with respondents through their responses. In the second phase, the interviews were deconstructed into their core themes that we later conceptually reordered and synthesized.

\section{Subjects}

Sara is a Jewish Israeli divorced mother of two who lives as a lesbian. She had suffered from childhood emotional and physical abuse by her mother, who was probably psychotic. She had spent much of her time growing up with her matemal grandparents. Her grandfather had sexually abused her. She was married at age 18, and had been physically abused by her husband. She had been referred for therapy because of severe occupational and maternal dysfunctions, marked anxieties, violent temper tantrums, and a diagnosis of DID. Seven personality alters were identified and worked with in psychotherapy spanning over a period of six years. At the time data were collected, she was 43 years old, living in a stable relationship, and held a steady job that provided economical security for her family.

Rebecca, a Jewish Israeli gay woman, had been exposed to traumatizing interparental violence as an infant. Her stepfather sexually abused her when she was between the ages of 6 and 14. Her attempts to recruit her mother's support resulted in disbelief and subsequent prolonged maternal abuse that was both emotional and physical. At age 14 she ran away from home and became involved in a lesbian relationship. The following years were characterized by promiscuity and prostitution. Her lover encouraged her to go into therapy. She was diagnosed at age 22 as suffering from DID. During her six years of psychotherapy, seven personality alters were worked with. At the time of the research interview, she was 29 years old, had completed her matriculation certificate, and was maintaining both a steady job and a steady relationship.

Irene, a successful North American Jewish academic, lived in Israel temporarily. She sought treatment during that time because of her deep depression. She was raised by a psychotic mother and grew up as a parental child who was constantly trying to ascertain the nature of reality, because she was frequently confused by the differences between her mother's representation of the world and her own perception of it. As a child, Irene had been raped by her father on numerous occasions. She was also frequently forced to receive enemas from her mother until she was 13 years old. Twelve alters were identified and worked with during her four-and-a-half years treatment. At age 22 Irene had divorced her first husband after two months of marriage. At the time of the interview she was 42 and reported she was living happily with her second husband.

Loraine, a North American professional working in Israel for a large multinational corporation, had never been involved in any meaningful relationship. This former patient grew up on a small isolated farm. Her parents were described as people who could not tolerate any display of emotional neediness and used to joke away her expressed distress and to dismiss it when she requested their 
nurturing. This emotionally starved child was also sexually exploited by her two older brothers between ages 5 and 17. After completing her university education she devoted her life to her career, working mainly overseas. When she entered therapy, Loraine presented with a "laughing mask" depression. In contrast with her very cheerful appearance, this patient complained of unrelenting morose moods and an unexplained self-hatred. Six personality alters presented themselves in her treatment. Psychotherapy lasted five years. At the time when the data for this study were gathered Loraine was 50 years old and working on her doctorate.

Tina, a single Dutch woman who taught elementary school, had completed a full decade of therapy two years prior to her research interview. Her father, a Lutheran minister, had sexually molested her when she was between the ages of 5 and 17. Tina had been addicted to alcohol and painkillers until age 30. She had been extremely promiscuous through most of her twenties. She had also prided herself in an ability to exploit men both financially and emotionally. Seventeen different alters were worked with until her final integration. During the research interview, which was conducted when she was 35 , she disclosed she still was suffering from bouts of depression and that she had been regularly attending a 12-step support group.

\section{RESULTS}

Our cross-sectional analysis of the respondents' verbatim yielded nine themes that captured best the experience of DID and their recovery from it: attitudes toward self and others; sense of identity; memory; belief in the veracity of memories; belief in the accuracy of the diagnosis; circumstances, awareness, and capacity for dissociation; fantasy life; spirituality and religion; and integration.

\section{Attitudes toward Self and Others}

A common feeling before therapy had been that life was a litany of endless pain and suffering occasionally combated with fantasies of grandeur. Sara talked about a constant feeling of rage.

I felt a need to avenge myself. . . I lived in an unbearably intense world of fierce and contradicting emotions. I was obsessed with sexuality and striven to be the world's best lover. I also felt that relationships were destructive and dangerous. ...

Rebecca described how unfocused and unsettled she perceived herself to be, in comparison to others. She talked about herself as having been "damaged goods":

Everything I touch turned into shit ... I was just not good enough for anybody to care about or respect me....

At the time she was interviewed, Sara finally felt she belonged to those who were "focused and settled down." 
Irene experienced herself during childhood as a prisoner in a concentration camp.

I felt I did not belong to this world. ... I was invisible to others ... they seemed mostly stupid to me, easily amused by trivial matters and untrustworthy. . . . in my "prison" the guards were crazy and could hurt me as they pleased. . . I was a broken person . . . living a joyless, melancholy life. . . . I believed I would never be able to join the world that others were living in.

Irene indicated that although she presently could see some others as reliable and benevolent, she was still uncomfortable with receiving kindness.

Loraine fluctuated between a lack of identity and a very negative experience of the self.

I had no identity of my own and I always wished I were someone else. I tried to blend-in like a chameleon but I remained lonely, isolated. . . I I always felt I needed to be fixed because there was something disgustingly wrong with me. I was different. . . . I knew I was never meant to be happy. . . .

Loraine reported that prior to therapy, she vacillated between feelings of worthlessness or impotence and grandiose feelings of omnipotence. The world had mainly been perceived as scary. During therapy her perception of the world had changed to the point that she saw it more as unfair:

The world owed me, because I was short-changed in life. . .

Following therapy, during her graduate professional education, she felt the world was providing her with interesting opportunities for growth and development.

Tina experienced herself as a "nobody":

I once had a mask and it was torn off my face only to reveal there was nobody underneath. . . . I couldn't relate to anyone because I did not know who I really was. .. . I had feelings of living with no ground under my feet. . . I had no basis ... no foundation. ...

I always depended on others to define their relationships with me and who I was. . . . That's why I sometimes felt great about myself but often felt more like a nobody.

When asked if those feelings were still pertinent she replied:

I am who now I am and that's not something bad at all. ... I have something valuable to offer.

\section{Synthesis}

This group of former DID patients talked about two main experiences concerning their perception of themselves and the world: 
1. The world had been seen as a tormenting, dangerous, and torturous place. Our respondents had mostly felt alienated and isolated from others. A profound sense of personal dehumanization emerged from their accounts. They grew up with self-images of undifferentiated, faceless, subhuman outcasts.

2. Their self-concepts prior to therapy had been portrayed as mainly poor but occasionally labile and shifting between polarities of worthlessness and worthiness.

We went back to our transcripts to try to identify possible sources for our respondents' occasional sense of positive self-regard. The few clues we found suggested that the choice of these children as sexual partners for their caretakers might have contributed to this outcome. It is conceivable that, as children, they had concluded there was something very "special" about them. This "positive" view, however, could not be sustained in an exploitative and abusive context.

\section{Sense of Identity}

A feeling of emptiness and confusion regarding their identities permeated these interviews. When specifically asked to describe the phenomenology of the self prior to their therapy a consistent pattern emerged.

Sara said:

... I felt I had no identity other than my sexual drive ... no feelings . . a dark internal emptiness and a constant craving for sex.

She also talked about a fragmented and contradictory sense of selfhood represented in her system of personality alters. These alters represented such incongruent and often incompatible identities as a loving personality (particularly toward the perpetrator), a murderously vengeful and angry self, a helpless child, and a man. Although she had sensed her multiplicity for years, Sara did not fully comprehend it and had occasionally feared she had been possessed by a demon. She admitted she had battled her alters in therapy, fearing she would be lost if they were allowed to continue. This initial resistance to the threatening reality of her fragmented self, gradually developed in therapy into a more cooperative mode of interactive communication through a diary and a more fair division of therapy time resources.

Today they are all me. I think the integration was a success because I am able to say I am (what used to be) "them." . . I I am able to feel their feelings simultaneously without having to switch.

Rebecca had difficulties articulating her pre-therapy sense of identity.

You are asking me to describe a void ... how can you describe a nothing? 
She later explained that for most of her personality parts the issue of identity was immaterial:

What was important was for the parts to be like the others out there, my personal identity was unimportant and in fact was quite irrelevant . . it was a feeling frightening confusion....

. . . in therapy this changed into a much clearer identity: I identified myself as a person with multiple personalities . . this had been who I was . . this became my reference group.

Today I am many lovely things, a mother, a partner, a professional. . . .

Irene had been trying to define herself through her activities.

I tried to build a "self" by developing skills and abilities. ... I was doing rather being ... I had derived a sense of who I was from the various projects I committed myself to. . . .

My identity was made up of parts that were images of me at different ages ... the parts were characterized by the main activity I tried to excel in during that period. For example there was this "eight-year-old choirgirl," or the "twelve-year-old ballerina." ...

... I realized how many there were only later in therapy. . . I had become a theater for this herd of circus elephants [Irene had a large collection of elephant statuettes she later identified as representing her inner world. ES].... I had to let them emerge and scream out their pain in therapy so I could get to know their feelings and memories rather than only know their achievements. . . . I developed a sense of responsibility for these parts and was committed to their well-being. . . . I insisted they all get their fair share of therapy time ... a lot of energy was invested in trying to establish some sort of internal continuity. ...

Today I can feel they are all there inside myself. . . I I can feel them jointly as being part of my unified identity but I can feel them separately as well. . . .

What I can say today about my identity is that I am wonderful . . (smiling)....

Loraine retrospectively described herself as having been a false person, a fake, and a hypocrite.

... I did things without knowing why. For example, I smoked because I wanted to be like others, but I don't think I wanted to smoke myself. I never quite knew what I truly wanted. . . . I pretended to want things depending on what I thought would be a good thing to say. . . .

I had a rich fantasy life and I liked pretending I was somebody else . . . although I always had a grip on reality, when I engaged in these fantasies I really felt I WAS [emphasized the respondent] that other person. . . . In situations that were hard for me to handle I would sometimes slip into that fantasy. I would act and feel as if I was somebody else. . . . 
. . . in therapy I came to terms with my lack of identity and I dreaded the switches. . . . I realized that, more often than not, they were not under my control ... these switches were confusing, tiring experiences. I tried to curb their occurrence. . . . Since I could not see the characters as part of me, I also couldn't make any sense of them . . gradually I accepted them as manifestations of me ... that was my first real experience of identity. . . I was DID .... and that's all that I was.

... therapy provided the environment to explore those aspects of myself . . . it was a painful process of introducing myself to my broken self. . . .

Gradually, the field of my self expanded in therapy and became better defined. ...

Tina's disorientation regarding her sense of self seemed to be related to her experience of missing time:

I never knew who I was . . there was an $I$ who was feeling and there was an $I$ who could tell my history and they did not match. ... I never really knew who I was beyond my name . . . my sense of myself was very vague. It was like a poorly edited recording with sections missing or a cacophony of different musical sections simultaneously played. . . .

The experience of missing time was also disorienting to my sense of who I was. ... I changed quickly without any control or understanding of the process ... one minute I was one way and the next thing I knew it was a different time and a different me....

Now I can give you a description of my self because time is not jumping anymore. The good sense of continuity I now have of my days and the things I do allow me to know who I am.

Synthesis

These respondents reported having had a sense of self prior to therapy that was disjointed and uncomfortably vacant. They used different methods to provide some orientation and anchoring. One such method involved self-definition through behaviors and achievements. Another type of effort to forge a sense of self was expressed by modeling the behaviors and expressed attitudes of others or by acting-out fantasized characters. The lack of a stable perspective of the self was described as a distressingly confusing experience that often was compounded by discontinuities in the experience of time. The first coherent sense of identity developed in therapy only after these former patients identified themselves as having been afflicted with DID. This identity had been mostly ego-dystonic. The respondents reported having tried to battle the emerging self-fragments in a desperate effort to regain control. The termination of therapy marked a clear improvement in this core experience. The post-therapy sense of the self was invariably described as complex but coherent and of positive valence. 


\section{Memory}

Sara was not able to provide a detailed account of her experience with her memory prior to the therapy. She remarked:

I may have remembered some of the major non-traumatic biographical events of my life, but otherwise my memory was very sketchy and contained more holes than substance . . . for a long time I couldn't even remember the day-to-day things. . . .

I had a vague awareness of traumatic abuse memories but I convinced myself they were fantastic inventions influenced by books I had read.

I first started to form memories during therapy. . . . I listened to the parts account their ordeals and this gradually began to register as familiar descriptions that turned into the substance of my memory ... one personality would share her childhood trauma in therapy and work it through. I would listen-in and later I could recognize the account as part of my biography, my memory.

... my memory was also forming through parts sharing various feelings and emotions. For example, I had a part that adored my perpetrator and stored good memories of him. I had only negative emotional memories of him. This was obviously a memory problem but neither of us lied . . . the integration of these different feelings helped me form my childhood memories. . . .

Today I have a continuous memory of my life that includes both my traumatic and my mundane memories. . . . I feel this is who I was. I feel connected to it. . . .

Rebecca related that her autobiographical memory had always been selective and that her day-to-day short-term memory had frequently been unreliable. She illustrated:

Before therapy began I remembered well only those things that were safe enough to remember ... from five years of repeated abuse by my grandfather I remembered only one incident. I had no recall of any of my mother's abusive behaviors.

I used to lose a lot of time and frequently got myself in trouble for forgetting to do things I was asked to do, or for losing stuff. . . . I remember inventing memorizing techniques to try to avoid the harsh punishments from my parents ... these daily memory problems continued to plague me throughout most of my therapy ... I used to miss appointments, PTA meetings and so on. ...

During therapy memories started to surface, but they were nothing like normal memories. . . . I experienced these recalled events with all my senses and emotions as if I were actually there. ... .

... only after I no longer had any buried memories did my day-to-day memory improve.

Irene's pre-therapy memory was also described as patchy, fragmented, and emotionally incongruent. 
I always had some recollection of my childhood but I only remembered discrete segments that were never connected... .

I had worked hard during therapy to inter-weave the compartmentalized accounts of my parts. I also collected information about the circumstances of my childhood. I looked for corroborating evidence. . . . I interviewed friends, neighbors, family members . . . it helped build-up my life story.

... I have a continuous and an easily accessible memory today . . . if I want I can remember events and the feelings that were associated with them. . . .

Loraine, too, reported partial amnesia for distressing childhood events. She had been deeply preoccupied with the accuracy of her memories throughout her therapy and beyond it. Here are brief excerpts from her lengthy comments on this theme:

.. . my traumatic memories were always conscious. . . . I feared them though . . . [I had] disturbing visual childhood memories . . . [they] had no emotional dimension ... the trauma memories were never laid out on a memory time line but I had all sorts of memory clues to figure out the different periods in my life in which these events took place. . . .

I had a very rich and active fantasy life and I often preferred to invest myself in my fantasies rather than experience the reality of the real world. . .

If a fantasized event seemed plausible, it was sometimes accepted as a fact and then remembered as an event that actually took place . . . if a real-life event did not fit with my mind set, I could make it seem as a fantasy of something that never really happened. . .

My daily memory function was never really good, but when my traumatic emotional memory opened up I started to lose time. . . . I used to feel the pain during the therapy sessions but forgot what the pain was about when I got back home. I could only remember I had an emotionally difficult session . . . during therapy my memory functions reversed . . . there were intense emotional remembering but little in the way of visual remembering. . . .

After I had integrated, my fantasy life became less dominant so I am better able now to differentiate between fantasized and experienced events. . . .

I now have a good continuity of memories that integrate both visual and emotional components. ...

Tina described a dialectical situation that involved "an ignorant knowledge" "a knowing without knowing," or, in her own words:

I came into therapy with a feeling that there was a big hole in my life. . . . I knew what happened but this big black hole took away my words for what exactly happened. . . . I knew that I had been abused but I couldn't tell you how exactly ... only after five years of therapy was I able to tell my story. . . . 


\section{Synthesis}

The experience of memory for these former DID patients was fairly consistent. None of the former patients reported suffering from complete amnesia for childhood traumata. Despite severe disturbances they had encountered in their daily and biographic memory functions, they all had at least rudimentary recollections of their childhood suffering. Their retrospective descriptions contained multiple utilization of the descriptor "holes" as representing the phenomenology of fragmented memory lines and the incongruity of pictorial memory fragments and their concomitant affect. Our respondents reported a continuous, accessible, and an emotionally congruent current memory (i.e., when the data were collected). They all claimed the reparation of their memory function occurred during therapy, mostly through listening to surfacing testimonies by disclosing alters.

\section{Belief in the Veracity of Memories}

Several former patients experienced some conflict with regard to believing their own trauma memories. Sara was very frightened by her traumatic remembering. She, initially, had to explore her memories under hypnosis. She offered the following remarks:

I never wanted to believe these memories were real. . . . I couldn't believe in them. I had repeatedly told myself these must be the result of things I had read somewhere.... I had no problem believing in my non-trauma memories....

I heard about this debate on memories being implanted under hypnosis and therapists' influence on their patients' memories. I think this is b.s.! I have no doubt about my memories. I feel they are mine. I know today what happened.

Rebecca reported she had little confidence in the truthfulness of her memories prior to therapy:

... the moment I was leaving the therapy session I started doubting the sincerity of the things I had just disclosed. . . .

I had this part that intentionally made me forget things she thought I was not ready to handle. ...

... during therapy, faith in my memories fluctuated. Only when a memory was coupled with emotion did it become real enough for me. As soon as I dissociated, the memory turned fuzzy and I started tormenting myself: "maybe you are distorting the whole thing, it couldn't possibly be real."...

Irene used to normalize her trauma memories:

I never doubted the accuracy of my trauma memories but before therapy they were not really very meaningful ... in fact they had an incorrect meaning attached to them. . . . I tended to normalize the crazy things that were done to me.... 
Loraine struggled with the validity of her reclaimed memories. She said, for example:

In therapy, new specific memories had surfaced but I was never sure about their accuracy ... some of the things that I present today as my memory could have been put there by me to fill-in the gaps. . . . I accepted these images as memories because they seemed to have been supported by others. . .

Today I have a better tolerance for ambiguity with regard to the truthfulness of certain specific details in my childhood memory, but I am still not always sure about them.

Tina indicated:

Before therapy I had no explicit memories so there was little to doubt. In therapy, the pictures came first, but when the feelings and emotions emerged I knew these couldn't possibly be fantasies.

\section{Synthesis}

Except for Loraine, who at the time of the interview continued to be uncertain about the source of some of her trauma memories, all our interviewees either had no access to their troubled past, at least at some point prior to their last therapy, or had experienced incredulity as to the veracity of some of their recollections. Analysis of the respondents' reports concerning this issue clearly yielded one common denominator. Their proclivity to believe their memories of childhood abuse depended on their ability to experience the images' concomitant feelings. Divorcing the abuse images from their meaning or emotional context rendered these memories unreal, and thus, much easier to disavow. Only after the images were re-contextualized in therapy could they be recognized as personal testimonies of their tormented childhood.

\section{Belief in the Accuracy of the Diagnosis}

Laymen and professionals alike find it difficult, at times, to believe in the validity of the dramatic manifestations frequently associated with DID. We asked our respondents to comment on their own reactions when they first learned about their diagnosis.

Sara presented in therapy with intense headaches and visions of blood that were suspected as possible pre-epileptic auras. She was sent for a medical evaluation to rule that alternative diagnosis out. She remarked:

... I really hoped I was epileptic. I wanted to take some pills and get over with these symptoms ... when it turned out I did not have epilepsy I knew I was doomed to live with my [internal] enemy and that there was nothing medically to be done. I felt imprisoned . . . this meant a prison sentence. . . . 
I so much wanted to be an epileptic because I knew I had multiple personalities and I did not want to have them. ...

\section{Rebecca said:}

The moment I was given my diagnosis I knew it was correct. . .

Irene began to examine her preexisting DID symptoms only after her condition was named:

When a diagnosis was suggested I was willing to test it as a hypothesis because it seemed plausible. This was precisely the moment my therapist's influence regarding the validity of the diagnosis ended. I had to explore this question myself. ... .

... I knew all along there were parts. I'd experienced these parts as being placed behind heavy steel doors. They'd lived inside their sealed compartments to prevent any leakage that could have drowned this vessel. . . .

Loraine had been struggling with the diagnosis:

... before therapy I had definitely sensed something was not quite right with me. . . I I used to think about my unusual experiences as somatic in nature.

When the diagnosis was given to me I was shocked. I fluctuated between belief and skepticism. ...

I felt a mixture of great interest in my inner world combined with much fear of it. . . I had been concerned I was making these parts up but I knew all to well that I was far from being that kind of a manipulator, so, I had to believe the diagnosis.

... I still feel distant, at times, from the diagnosis . . . as if the parts might have been only metaphors for my internal disintegration. . . .

... the moments I most believed the diagnosis [was valid] were those in which I switched from feeling to feeling: from panic to depression to anger to sorrow. . . without any context without control . . . this was a chaotic world of confusion.

Tina indicated that throughout her therapy she and her therapist preferred not to use the label of DID.

... we felt it was too stigmatizing. . . . I became more comfortable referring to my former diagnosis only after I had integrated. . .

\section{Synthesis}

DID can, initially, be an elusive disorder for both clinician and patient. The essence of this defense system is the compartmentalization of threatening knowledge with concurrent unawareness of both the contents of the dissociated material and the dissociative process itself. Patient acceptance of the DID diagnosis cannot, 
therefore, be like the acceptance of any other psychiatric diagnosis. This descriptive label can expose the patient to the essence of his or her defense system. Frequently, this happens relatively early in therapy when the admittance that dissociative defenses are utilized can be challengingly premature. For a memorydisowning trauma survivor to believe in the validity of a DID diagnosis, often constitutes a compromise of the old defense mechanism and an initial step toward the recognition of the disavowed past. Our respondents had shown varying degrees of preparedness to do so.

\section{Circumstances, Awareness, and Capacity for Dissociation}

We asked our respondents to describe their experience with dissociation and any changes they might have noticed in their dissociation experience over time.

Sara answered in terms of her control of the phenomenon:

I gained some control over my dissociation only during the last two years of therapy. Before that dissociation always appeared automatically in distressing situations. ... .

. . . after I had integrated I became in charge of my dissociation. I used it to gain better control over my feelings ... when I needed to be rational.

Nowadays, I am not able to dissociate anymore. In the old days, when I dissociated I switched to a different personality that could feel. Today when I try to dissociate I get all clogged-up emotionally, I hate it. . . .

Rebecca described the usefulness of this defense mechanism:

Emotions just got in the way of survival . . . I couldn't think straight with all these painful feelings floating around, so I just put them in a box.

There were moments during my childhood that I absolutely had to ignore my physical pain and I know I couldn't consciously make that happen. . . I I didn't even know I was doing it, dissociation just happened. . . .

During therapy I had discovered I could voluntarily activate dissociation . . . dissociation became a resource I used to enhance relationships with. For example, I used to allow a childlike part of me to emerge during play with my daughter....

I can consciously dissociate today and I sometimes do it when I get scared . . . last time I did it when I was audited by the IRS. I made the IRS man disappear in front of my eyes. A writing hand became his only remaining visible body-part ... no [personality] part was actually taking over. I had deliberately done this.

Irene shared her appreciation of this mental process:

Dissociation used to be an automatic habit that protected me from pain and discomfort. Today, I still need to consciously work against automatic dissociation. I don't like automatic dissociation because it interferes with my 
ability to be in touch with my senses and gets in the way of my being fully aware of what is going on.

After I was done with my therapy, I found out that I could use dissociation to my advantage. When I am emotionally unwell and I can't tell what is exactly bothering me, I go inside and I look for the part of me that is distressed. For example, recognizing that my sudden inexplicable sadness in the office was the reaction of the 7-year-old girl me feeling unappreciated by a very critical client, was enough to alleviate my distress.

... it is a controllable process that allows me easy access to my subconscious....

Loraine described how involuntary dissociation has been in her life:

Before my therapy dissociation was mostly a scary experience. I hated the loss of time. ...

... there were times when I had seen myself as if I was watching a movie....

During quiet times, for instance when I was reading a novel or daydreaming I used to "disappear.". . . I lost my bearing, my identity. . . .

In therapy I learned to identify the situations and events that triggered dissociation. ... I learned to identify the process. ...

My capacity to tolerate stress is by far better now than at any previous time in my life. ...

There was one incident following my integration that dissociation did kick-in again. . . . I was anxious and panicky and, then, I suddenly sensed a change. ... I went to the mirror and there was somebody else there.... I let it happen ... I did not fight it ... this WAS helpful.

Tina talked briefly about dissociation as a mechanism that had been a very effective remedy to her emotional pain and to the burden of her trauma memories. She added:

... it helped me ignore intense feelings. . . .

\section{Synthesis}

Tina's concise reply nicely represents the contradictory dialectics of pathological dissociation that enables a simultaneous knowing and not-knowing. With the help of dissociation she was simultaneously in intense pain and in comfortable ignorance of it. Although much appreciated as a potent psychological anesthetic at times of duress, the shielding experience of dissociation was also described as distressful. Pre-therapy accounts of this defense mechanism included a portrayal of dreaded loss of time and compromised self-control. Peri- and post-therapeutic accounts described increasing awareness and command over the dissociative process and the circumstances of its occurrence. Rebecca, Irene, and Loraine 
reported that they continued to benefit from their dissociative abilities long after they had integrated. Irene described the current state of her personality as endowed with a special structural flexibility. Notwithstanding a remnant of an involuntary personality dysfunction, she had dubbed this ability "voluntary creative disintegration" and regarded it a most advantageous gift and a valuable tool for psychological exploration and preventive self-care.

\section{Fantasy Life}

When asked to describe the role imagination played in her life, Sara described aggressive fantasies:

I used to spend a lot of time engrossed in violent fantasies. . . . I visualized in minute detail fighting and beating up my opponents. . . .

... I had fantasized a perfect world in which I was all-powerful . . in which nothing and nobody could hurt me. ...

. . . this fantasy world had really hurt my judgment . . . [subsequently] I had made some very poor decisions that were based on my exaggerated confidence. ... .

... bureaucrats have always scared me.... I used to project all sorts of horrible fantasies on various officials and about how they would hurt me. It got to the point where I couldn't deal with simple errands if they involved talking to a clerk.

Rebecca described how the occult played a role in her imaginary life:

[as an adolescent] ... I had worlds that were not related to my alters . . . I also lived in a realm of sorcery ... with extra-terrestrial enemies that were defeated by the counter-magic my girlfriends and I were casting. . . .

... my fantasy world became very important to me . . . I even managed to get some of my friends to participate in interactive fantasizing. . . .

There were periods in which I actually believed I could cast spells or that I could fly. ...

.. . later on I used reading as an escape . . . I used to get immersed in the novels I was reading ... that does not happen much anymore ... I tend to become engrossed in the Internet, though. . . .

Irene described how she was immersed in imaginings of her performances:

I used fantasy as an escape. . . . I remember leaving the body in my bedroom to perform imaginary ballet routines. These were kinetic fantasies.

When I first started to immerse myself in professional life, the fantasies shifted from dancing to anticipatory problem-solving fantasies . . . these reveries represented real-life future challenges. . . . I would rehearse various solutions in mind. ... 
I am a very focused person today ... anchored in the things I do.

Loraine often lived in her fantasies more than in reality:

... my fantasy life was very dominant until well into my 40's. It lasted until the end of my first year in treatment ... it consumed considerable amounts of my time ... I used to spend hours at a time in a make-believe world complete with imaginary friends and exciting espionage adventures . . . there were also sado-masochist themes. ...

I used to invent whole separate biographies for myself. . . I lived parallel lives. ... I sometimes acted these characters out. I think this became a venue for my inner parts to express themselves.

Another form of fantasy I had involved identification with good authority figures in my life ... my elementary school teacher, my school teacher and then you [the therapist].

I used to hold elaborate, lengthy, and vivid discussions with these figures . . . sometimes I couldn't tell if certain conversations occurred in reality or in my mind.

I identified so much with these persons I occasionally became them . . . through them I managed to forge my own identity.

It affected the quality of my professional functioning . . . I wasted a lot of time ... there are details of my autobiographic memory that to this day I am not sure if they really happened or if I just made them up.

Today I'd rather spend more time with myself. I need to get to know myself better ... fantasy is for people who don't have a strong identity.

The following excerpts described Tina's polarized fantasies:

I had two types of fantasies: Fantasies of grandeur and fantasies in which I had been threatened and exposed to danger. . . .

I used to spend hours day-dreaming about success and fame. . . .

... on my way to my therapy sessions I had often fantasized myself walking through a forest and then being attacked from behind by someone with a knife. . .

As therapy progressed these fantasies persisted but I noticed that I became better able to defend myself against my assailants. . . .

I also had this persistent hostage fantasy. . . . one of my alters fantasized that she kidnapped me and held me as her hostage. . . I became so absorbed in her fantasy that it became my reality . . . there was a time I was held hostage for seven whole months. I hadn't shown-up in therapy ... finally, my therapist tracked me down and I was freed. 
Other ongoing fantasies have to do with my anger. Erica, one of my parts was flooding me with her pyromaniac images. I fantasized I was constantly carrying this little jerrycan full of gasoline and setting many of the campus buildings ablaze.

. . . nowadays, when I get real angry with someone I still fantasize that I am burning or shooting that person to death.

\section{Synthesis}

Fantasy played a central role in the life of these respondents. It became a viable alternative reality to a bitter existence forced upon them during childhood. Their phantasms provided for compensatory empowerment not only through imagined retaliatory aggression (Sara, Tina), possession of privileged information and skills (Loraine), paranormal powers (Rebecca), and physical agility (Irene), but also through imagined social interaction and nurturing (Loraine). So compelling were their daydreams that they compromised reality testing and daily instrumental functioning (Sara, Rebecca, Loraine, and Tina). The contamination of inner and outer worlds was also evident in projections of fear (Sara) and rage (Tina). Fantasy and the dissociative process are closely related. Not only do the two phenomena co-occur, but they also provide an optional respite for unendurable hardships, both involve gripping experiences that activate a multitude of senses and emotions, and both can interfere with reality testing and quality of daily functioning.

\section{Spirituality and Religion}

Although not a believer in God, Sara saw herself as deeply spiritual:

My spirituality was expressed through my creativity. I created through my pain and the art piece, in turn, gave meaning to my pain.

. . . when I realized that the better I got the less able I was to write my poetry, I considered quitting therapy . . . that's how inspiring and meaningful art was to me. . .

I never wanted to have anything to do with organized religion.

I gave up on God's religions so I created my own faith. I believed in ghosts and demons and practiced channeling with spirits.

This was all somehow related to my inner demons. . . . I don't relate to this anymore these days.

Rebecca struggled with her Jewish identity:

... during high school I contemplated becoming a born-again Orthodox Jew to ensure that "everything would be all right."

I have always been interested in religious matters . . . I have been interested in worship, in black magic, and Christian liturgy. . . . 
Every form of moderate religion is a vehicle to connect with the eternal and the good within you....

I am confident that all I have gone through and all the years of suffering were so I would learn something from it. I hope I will be able to discover what it was that I was meant to learn before I pass on . . . this approach has helped me avoid holding any grudges or bitterness against anybody. ... .

Irene rejected her family's faith:

I was brought up as a Christian but I had abandoned the faith long before I converted to Judaism. . . .

I had difficulties with Christianity because of how fragmented and divided it was. I guess it reflected the difficulties I experienced with my own internal fragmentation. ...

There was a period in my life when I lacked any spiritual anchoring, this was a dangerous situation for me...

Religion has provided me with an experience of justified existence . . (my needs were never ackowledged as a child ... I learned to doubt my right to exist ....).

... religion has contained me, supported me when I stumbled and fell . . . in times of distress it provided me with the hope that there was a better place awaiting me beyond the painful chaos I was living in. . . .

Loraine described her conflicted relationship with God:

During the time my abuse was going on I turned to God for help. . . . I hoped religion would help bring about the change I so much needed.

Religion lost all meaning for me after I was badly injured in an automobile accident when I was 18 years old.

... I had continued my search for a suitable religious belief until I had finally found one....

In therapy I got very angry with God. I needed to understand how and why God had allowed this abuse to happen.

Spirituality develops from integrating knowledge, feelings [of love] and behavior. Dissociation interfered with my spiritual development. I used to be a disconnected self-centered person. Therapy enabled me to find love for myself . . . this helped me discover God's love and my ability to be empathic for others. . .

Tina denied God's existence:

I have been an atheist from a very young age. My father, the perpetrator, was a Protestant Minister. . . . 


\section{Synthesis}

The five recovered survivors of child abuse we interviewed for this study had had an active preoccupation with spiritual and religious matters. Noteworthy is the fact that not one of them had developed her spirituality within the organized religion in which she had been brought up. Tina, the daughter of the abusive Minister was a firm non-believer. She struck us as being angrily defiant against God's authority through her sullen denial of his existence. Sara also had renounced God, but had been actively searching for contact with spiritist entities. Rebecca, on the other hand, never gave up on her belief in God. Although she never found the suitable religious framework she had been seeking, she remained deeply spiritual. Irene abandoned her parental religion but continued to cherish her faith that provided her with ongoing sustenance and hope. Loraine perceived her spiritual development as having been stifled by the dissociative disorder. She had constantly been in one form of dialogue with God or another.

The pain endured by our respondents had influenced their spiritual quest and helped form their final stance vis-a-vis God and organized religion. It seems that for these survivors spirituality provided a much needful humanizing and nurturing connection to an external source of benevolence and to the good within them.

\section{Integration}

Here is some of what Sara said about this advanced stage of her healing:

[Responding from the host-personality's perspective] . . the first integrations were either with parts that I cherished, valued, or wanted to keep . . . like the "hurt little girl," for example. The last parts to integrate were with those aspects of me that I had difficulties accepting, like my feminine part or the part of me that had some positive regard for the perpetrator.

When the first [partial] integration came I felt something had happened. I felt struck and then I knew it was happening.

My last integration was not consciously initiated. It just happened. Just like that. There was an immense flash and then I knew I had been integrated.

It was both frightening and exciting. Afterwards, things that used to threaten me did not seem threatening at all anymore. . . I I felt great.

\section{Rebecca disclosed:}

The notion of integration was initially quite scary for me ... it was pretty much like I was having to die. . . .

[Integration was] ... a result of a collaborative process involving two or more alters. These were like "think tanks" that started to produce sudden insights. These insights became more and more frequent until, finally, I found that I had 
a consistent ability to understand what was going on. That's when I was fully integrated.

Today I feel I am fully aware and present both as the collective of parts and as any individual part. That is, even when a part of me is present, there is a collective awareness of the experience.

It rarely happens, nowadays, that a part would actually come out. If anything like this ever happens it is only during a sexual experience ... it is not for coping with distressing situations anymore. On the contrary, it is to enable different aspects of me to grow through participation in new experiences.

Irene shared the following:

My internal voices were recognized through my writing. When I wasn't feeling very well I used to write down their dialogues. I, then, read them, trying to understand the reason behind the distress . . . as if this was another person's problem.

It gradually dawned on me that I could get some relief if I paid enough attention to the voices and their pain. I understood they needed to be heard....

My integration is about being in control, being aware, being able to understand myself. ...

Whenever I'm anxious and I can't understand why, I turn inside and I ask: What's going on? I usually get an answer that either helps me deal better with an external problem or guides me as to how to calm myself down. . . .

There is a clear advantage to my situation: I have better access to my subconscious than most people do. I call this ability Creative Disintegration.

Here is a sample of some of Loraine's main comments on this topic:

I think that the best way to describe my integration process is as a progressive one. First, there were brief moments of integration; later on I was integrated during some of the time but wasn't on other occasions. This developed into a period in which I was integrated most of the time and then, into full integration with only momentary periods of disintegration.

It is a process of forward and backward movement on the dissociation continuum, but the general trend is towards a decrease in dissociation.

As internal unity increased the shifting between internal beliefs, and feelings of identity gradually decreased. ...

Integration was an ongoing process that has resulted in the gradual consolidation of my personallity . . . there was no specific point at which I was suddenly integrated. We are talking about a process....

... once you're integrated, you don't feel fragmented anymore, but in emergency situations there is a proclivity to utilize the mechanism for brief periods of time to help with coping. . . . 
It wasn't my last integration that was the most significant one in my healing. The whole process was important.

Tina revealed:

Integration does not occur in a single moment but rather it is a lengthy process. ... It brought with it an experience of continuity ... when I encounter difficult situations I don't get stuck anymore and there are no more switches. . . I have the flexibility necessary to handle many situations now....

When the $\mathrm{s}_{-}{ }_{-}$hits the fan the mess does not evade me as it used to before I integrated. I experience the whole deal now . . . nobody takes over for me anymore.

There were times after I had integrated that I felt very lonely. . . I had a hard time getting used to the idea that I had to face it all by myself.

\section{Synthesis}

It is noteworthy that integration was not always described in terms of a renunciation of dissociative capabilities. Rebecca, Loraine, and even more so, Irene described occasional post-integrational awareness of the old psychological entities that once formed the personality alters. Rebecca described an awareness of these states at times of exceptional excitement. Loraine infrequently experienced their defensive function at times of emergency, whereas Irene regarded them as accessible mental faculties capable of providing her with valuable insight into perplexing distressful conditions. It is also noticeable that the placements of these former patients on a hypothetical uniformity/rigidity-complexity/flexibility continuum of personality structure were not consistent. Whereas Sara and Tina talked about their lives as "one," others were clearly continuing to utilize some of the advantages of the dissociative process. It is probable, though, that rather than representing "imperfect" integrations this variance portrays the naturally occurring distribution of dissociative phenomena in the population. It is, perhaps, not only an unreasonable expectation but also an undesirable outcome to have a useful defense mechanism, naturally occurring in society, completely abolished in this particular population. Irene's description of her productive consultations with former parts, termed by her "creative disintegrations," is reminiscent of the Watkins and Watkins concept of "ego states" [13]. For somebody like Irene, a satisfactory recovery may have also involved moving from defective control and awareness of her dissociated alters to enhanced awareness and productive utilization of what could be post-therapeutically termed as normal ego-states.

\section{DISCUSSION}

The results of this qualitative analysis encouraged us to reexamine and highlight four theoretical issues associated with the phenomenology of pathological 
dissociation and the recovery from it: The role of spiritual- and imagery-based altered states of consciousness in DID, the convergence of borderline and dissociative nosologies, conditions for the reassociation of traumatic memories, and criteria for a successful resolution of DID.

\section{The Role of Spirituality, Imagery and Fantasy in DID}

Fantasy played an important part in the phenomenology of our respondents and seemed to have fulfilled a significant role in their everyday coping. They also reported an active interest with spiritual and religious matters. Many survivors of childhood abuse maintain distorted images of God developed in their families of origin [14]. From the perspectives of many abused children, God is seen as a powerful enemy and a source of threatened punishment. Gorsuch postulated that such negative perceptions of God are modeled from the child's experiences of parent figures and taken in as parental introjects [14]. May reported another variation in the spiritual process of survivors [15]. Some of them maintain a hope of turning over a defective self to a God who can offer what their parents never could: protection from suffering, comfort, and soothing. The similarities between fervent worship and altered states of consciousness have been noted previously [e.g., 16, 17]. A capacity for deep absorption has often been observed in many religious practices. In fact, possessive symptomology and trance-like spiritual absorption are said to exist in 90 percent of 480 investigated cultures [18]. Religious absorption, daydreaming, and hypnotic trance are similar mental processes in that conscious awareness is focused on objects, images, ideas, or events and not on the self. Kirmayer suggested that in these kinds of mental states, people are essentially unaware of the self and are more or less absorbed in the external world - even when that world occurs within their own bodies [19]. Reverie can be especially rewarding for those who need to separate themselves from a troubling experience of the self. Future research is needed to further explore the role of spiritual absorption as a coping method in victims and survivors of trauma. Wilson and Barber claimed that reverie is not a rare human condition $[20,21]$. As much as 4 percent of the population could be characterized as fantasy prone, a trait, they claimed, that represented adaptive experiences and fantasy abilities. Other investigators go as far as proposing that multiple personality without amnesia is a normal individual difference that results when emotionally incompatible self-images are fantasized and upon which dissociative reactions to trauma (like amnesia) may be superimposed [22, 23]. Several authors have suggested that fantasy and imaginative involvement could be important developmental substrates of dissociation [e.g., 24, 25]. Two lines of investigation endorsed a possible connection between imagery or fantasy and dissociative phenomena: 1) imaginative involvement (Absorption) was identified as a valid factor in the Dissociative Experiences Scale, the most widely used dissociation 
scale [26, 27]; and 2) statistically significant correlations were found between scores of imaginative involvement and hypnotizability and measures of dissociation $[28,29]$. Intensive interview studies have shown that excellent hypnotic and fantasy prone subjects report a longstanding history of imaginative involvement and a link between these tendencies and exposure to an aversive childhood environment, including physical and sexual child abuse [20, 30, 31]. One indication of high imaginative involvement is the incidence of childhood imaginary companions. Nagera noted that the most critical function of an imaginary companion is to guard the child from rejection, loneliness, and/or neglect [32]. Sanders found that 64 percent of adults with DID surveyed recalled one or more imaginary companions. Most of the respondents could see or hear their imaginary companions or believed they were real [33]. Dierker, Davis, and Sanders showed that students who remembered their imaginary companions were found to be more dissociative than those who reported not having a companion [34].

Our findings are consistent with Hilgard's hypothesis that extensive fantasy involvement constitutes a way of coping with or escaping from harsh or aversive childhood environment [35]. Many survivors of childhood victimization learn to associate relationships with aggression. As a result, some try to avoid interpersonal closeness, whereas others actively engage in violent relationships either as victims or as perpetrators. A number of studies have shown that male abuse survivors tend more than female survivors to be aggressive against people they are closely related to [e.g., 36, 37]. Empirical data on gender differences in fantasy involvement is extremely scarce and suggests a somewhat higher proclivity for imaginary activity among females $[34,38,39]$. Because none of our respondents had any known history of violent behavior, we wondered whether female victims of child abuse tend to utilize fantasy involvement as a vehicle for processing pent up rage. Bliss reported that 67 percent of a group of convicted male sexual offenders may have experienced self-hypnosis processes [40]. He postulated that these processes initially put the male perpetrators at a distance from their victims allowing them to perform acts that ordinarily would be a taboo, and subsequently defend against awareness of the perpetration. Further research is required to find out to what extent the conversion of childhood victimization into adult perpetration is mediated by gender-dependent capacity for imagery involvement and processing (as employed by the non-offending female survivors investigated in this study) and by peri-offensive dissociation (as employed by the male sexual offenders studied by Bliss).

\section{Convergence of Borderline and Dissociative Symptomatology}

Our analysis revealed several overlapping Borderline Personality Disorder (BPD) features among our respondents: they reported dichotomous thinking or splitting; they had been struggling with contradictory views of their self-worth; 
they had experienced isolation, alienation and had suffered feelings of being social misfits; they had been confused about their own identity and tended to scan internal and external environments for clues on how to behave; and often their identities had been defined in terms of their behaviors and interactions and, thus, remained labile. BPD theorists also have pointed out the difficulty of placing current affective events in their wider relational context [41, 42]. Williams saw this BPD feature as a failure in autobiographical memory, an essential DID feature that was prominent among our respondents [34]. The two disorders are reported to have other common characteristics, including self-injurious behaviors, depression, anxiety and depersonalization [44]. The five respondents in this study were victims of incest. A history of sexual abuse, particularly incest, was reported as a biographical feature in the lives of 75 percent of DID patients [e.g., 45]. The reported prevalence of child sexual abuse in the histories of women meeting criteria for BPD was 75 percent [46] and 86 percent [47]. Consequently, investigators in the field are not in agreement on whether DID is a distinct diagnostic entity or a variation on BPD [e.g., 48]. Despite the great similarity between the two diagnostic entities, a few significant differences were noted. Individuals diagnosed with DID tend to report more Schneiderian first-rank symptoms, greater severity of childhood sexual abuse, greater severity of amnesic episodes, and fewer endorsed symptoms of BPD [49]. The recent addition of "severe dissociative symptoms" to the list of possible DSM-IV diagnostic criteria of borderline personality disorder [50] may add to further diagnostic uncertainty. Adding to this confusion is the evidence that the dual diagnosis of DID and BPD might constitute a distinct diagnostic category similar to schizoaffective disorders [51]. We believe that common etiological and clinical factors may justify the formulation of a new DSM-IV posttraumatic spectrum of disorders that will include Acute Stress Disorder, Posttraumatic Stress Disorder, severe dissociative disorders, and BPD. However, further research is needed in order to establish the degrees of divergence of borderline and dissociative symptomatology. Marmer and Fink argued that the DSM blurs these two disorders by its emphasis on phenomenology over inner structure [52]. Emerging psychological testing data suggest highly distinctive features of psychological process and personality structure that may accurately differentiate between these two disorders [53, 54]. We propose the development of reliable psychodynamic diagnostic tools that will better identify BPD forms of splitting, characterized by polarizing, and the ego splitting characteristic of DID patients.

\section{Traumatic Memory, Dissociation, and Reassociation}

Our respondents entered their final therapy with a variety of distressing signs. Prominent among their symptoms were problems with memory. These types of disturbances were said to be characteristic of this population [55]. Despite severe 
disturbances in daily and biographic memory functions, all our respondents had some recollection of their childhood ordeals prior to their DID treatment. Their memory dysfunction manifested in a phenomenology of fragmentary narratives and an incongruity of pictorial memory segments and their concurrent affect. Dissociation in these former DID patients involved an ability to segregate and idiosyncratically encode traumatic experience and other autobiographical memories into separated mental processes with remarkable fluidity in identity. These survivors of childhood trauma learned to process overwhelming experiences in an unintegrated manner. The treatment these respondents received was focused on their pathological dissociative processes rather than on uncovering past trauma. Contrary to orthodox psychodynamic approaches, DID was not construed as the result of unconscious defenses serving a weak ego in the face of intolerable affects, leading to "hysterical" symptoms. The therapists of this study reified personality alters by allowing them to be the focus of treatment. Psychotherapy with these former DID patients focused on reducing separateness and conflict among alters and on achieving congruence of perception by dealing with buried traumata and affect within a strong therapeutic alliance that maintained a secure frame and firm treatment boundaries.

According to some skeptics, DID is a social construct that is inculcated by therapists. In their view, a treatment approach that acknowledges dissociative pathology would encourage suggestible patients to disavow responsibility for their actions and deepen their psychopathology [56, 57]. The dissociationfocused treatment outcome in this DID sample showed different results. Not only did our respondents benefit from the treatment but they also claimed that the reparation of their memory function occurred during that therapy. Our patients' inclination to believe their uncovered childhood narrative was not a product of the therapists' coercive suggestions that healing required the production of personality alters and traumatic memories [58]. Their proclivity to lessen their own doubts regarding the veracity of the incredible childhood images that haunted them and to believe their own traumatic memories depended on their ability to lessen their pathological dissociation and to experience the segregated emotional "sound track" concomitantly with the troubling memories. We believe that the successful outcome of the trauma- and dissociation-focused treatments offered to this DID sample supports the new traumaterigic paradigm suggested by Loewenstein and Ross [59]. The treatment perspective derived from their thesis and adopted by the three therapists of this sample aims at fostering the metabolism of shattering traumata that were unrelenting and unremediated. The favorable outcome of the "DID treatments" reported by our respondents adds further validation to the DID construct. Notwithstanding, the paucity of outcome research in DID is troubling. It is hoped that this qualitative study will encourage controlled research in this poorly investigated area in psychotherapy. 


\section{Integration}

All five respondents in this study were leading productive and emotionally balanced lives. Nonetheless, they differed on the degree and circumstances of their post-therapy utilization of dissociative defenses. They even differed in the degree of cohesiveness of their personality unification. One of our respondents, Irene, a highly functioning former DID patient, declared she greatly appreciated her retained capacity to identify subconscious processes by invoking what she termed a "creative disintegration." This process allegedly enabled her to consult productively with (now only vaguely distinct) former personality parts. Irene, like Chase [5], belongs to a minority of DID patients who are opposed to any change in their system of alters. No controlled studies offer any evidence as to the superiority of either approach. However, Kluft reported that 94 percent of 52 DID patients who were successfully treated to achieve integration reported enhanced quality of life and continuing gain $[60,61]$. Two of his integrated patients reverted back to their DID condition. Kluft also reported that most patients who left treatment without achieving integration often relapsed into dysfunctional dividedness under duress [62]. He conceded, however, that it is possible for some DID individuals to cope well while divided. This would be especially true when other aspects of the mind do not assume executive control, there is no important behavior that is disowned and disremembered, there are no longer changes of identity and selfpresentation, and no barriers are left to isolate conscious awareness from important episodic memory. The option of a non-integrational resolution of DID was explicitly advocated by Goulding \& Schwartz in their book entitled The Mosaic Mind [63]. Phillips and Frederick suggested that integration should be viewed as spanning an entire continuum of possibilities for relationships among ego states - from the most completely separated to the state of personality merging [64]. Hermans proposed defining the self in terms of a dynamic multiplicity of relatively autonomous $I$ positions [65]. Watkins and Watkins claim that segmentations of the human personality that occur in the intermediate range of the differentiation-dissociation continuum are less obvious [66]. In their book, they explain that normal ego states come about through adaptive segmentation by the personality in solving fairly normal problems of living. They define ego state therapy as follows:

Ego state therapy is the use of individual, group, and family therapy techniques for the resolution of conflicts between ego states that constitute a family of self [66, p. 96].

Ilene's account of her post-therapy "creative disintegration" process for solving her normal problems of living is in line with the concept of ego states' personality. Controlled research is needed to document the distribution of personality cohesiveness in the normal population and the relationship between this variable and emotional well being. Future research should also determine which 
approach to DID therapy-outcome is superior: the unification approach or the adaptationalist/ego state approach.

\section{ACKNOWLEDGMENT}

We wish to thank Martine Hueting for her assistance with the translation of the Dutch interview.

\section{REFERENCES}

1. M. Cooper, If You Can't Be Jekyll Be Hyde: An Existential-Phenomenological Exploration on Lived-Plurality, in The Plural Self: Multiplicity in Everyday Life, J. Rowan and M. Cooper (eds.), Sage, London, 1999.

2. D. Bryant, J. Kessler, and J. Shirar, The Family Inside: Working with the Multiple, W. W. Norton, New York, 1992.

3. D. Bryant and J. Kessler, Beyond Integration: One Multiple's Journey, W. W. Norton, New York, 1996.

4. C. C. Sizemore and E. S. Pittilo, I'm Eve, Jove Books, New York, 1977.

5. T. Chase, When the Rabbit Howls, Jove Books, New York, 1987.

6. J. G. Watkins and R. J. Johnson, We, The Divided Self, Irvington Publishers, New York, 1982.

7. E. Somer and A. Weiner, Dissociative Symptomatology in Adolescent Diaries of Incest Victims, Dissociation, 9:3, pp. 197-209, 1996.

8. L. Somer and E. Somer, Phenomenological and Psychoanalytic Perspectives on a Spontaneous Artistic Process during Psychotherapy for Dissociative Identity Disorder, The Arts in Psychotherapy, 24:5, pp. 419-430, 1997.

9. Y. S. Lincoln and E. E. Guba, Research, Evaluation, and Policy Analysis: Heuristics for Disciplined Inquiry. A Position Paper. Earlier versions of this paper were presented at the Annual Meeting of the Evaluation Network/Evaluation Research Society (1983) and the Annual Meeting of the American Educational Research Association (New Orleans, LA, April 23-27, 1984), 1985.

10. J. P. Spradley, The Ethnographic Interview, Harcourt, Brace College Publishers, New York, 1979.

11. N. K. Denzin, Interpretive Interactionism, Sage, Newbury Park, California, 1989.

12. M. Q. Patton, Qualitative Evaluation and Research Methods (2nd Ed.), Sage, Newbury Park, California, 1990.

13. J. G. Watkins and H. H. Watkins, The Theory and Practice of Ego State Therapy, in Short-Term Approaches to Psychotherapy, H. Grayson (ed.), Human Sciences, New York, pp. 176-220, 1979.

14. J. Gorsuch, An Invitation to the Spiritual Journey, Paulist Press, New York, 1990.

15. G. G. May, Addiction and Grace: Love and Spirituality in the Healing of Addictions, Harper \& Row, San Francisco, 1988.

16. I. M. Lewis, Ecstatic Religion, Routledge, New York, 1987.

17. M. Shafi, Freedom from the Self: Sufism, Meditation and Psychotherapy, Human Sciences Press, New York, 1985. 
18. E. Bourguignon, Psychological Anthropology, Holt, Rinehart \& Winston, New York, 1979.

19. L. J. Kirmayer, Pacing the Void: Social and Cultural Dimensions of Dissociation, in Dissociation: Culture, Mind and Body, D. Spiegel (ed.), American Psychiatric Press, Washington, D.C., 1994.

20. S. C. Wilson and T. X. Barber, Vivid Fantasy and Hallucination Abilities in the Life Histories of Excellent Hypnotic Subjects ("Somnambules"): Preliminary Report with Female Subjects, in Imagery: Vol. 2. Concepts, Results, and Applications, E. Klinger (ed.), Wiley, New York, pp. 133-160, 1981.

21. S. C. Wilson and T. X. Barber, The Fantasy-Prone Personality: Implications for Understanding Imagery, Hypnosis, and Parapsychological Phenomena, in Imagery: Current Theory, Research, and Application, A. A. Sheikh (ed.), Wiley, New York, pp. 340-390, 1983.

22. D. Barrett, Fantasizers and Dissociaters: Two Types of High Hypnotizables, Two Different Imagery Styles, in Hypnosis and Imagination, R. G. Kunzendorf, N. P. Spanos, and B. Wallace (eds.), Baywood, Amityville, New York, pp. 123-135, 1996.

23. R. G. Kunzendorf, M. Crosson, A. Zalaket, J. White, and R. Enik, Normal Dimensions of Multiple Personality without Amnesia, Imagination, Cognition and Personality, 18, pp. 205-220, 1998-1999.

24. K. S. Bowers, Dissociation in Hypnosis and Multiple Personality Disorder, International Journal of Clinical and Experimental Hypnosis, 39, pp. 155-176, 1991.

25. W. C. Young, Observations on Fantasy in the Formation of Multiple Personality Disorder, Dissociation, 1, pp. 13-20, 1988.

26. C. A. Ross, S. Joshi, and G. Anderson, The Dissociation Experiences Scale: A Replication Study, Dissociation, 1, pp. 21-22, 1991.

27. C. A. Ross, J. W. Ellason, and G. Anderson, A Factor Analysis of the Dissociative Experiences Scale (DES) in Dissociative Identity Disorder, Dissociation, 8:4, pp. 229-235, 1995.

28. D. Segal and S. L. Lynn, Predicting Dissociative Experiences: Imagination, Hypnotizability, Psychopathology and Alcohol-Use, Imagination, Cognition and Personality, 12, pp. 287-300, 1992-1993.

29. C. H. Smyser and D. A. Baron, Hypnotizability, Absorption, and Subscales of the Dissociative Experiences Scale in a Nonclinical Population, Dissociation, 6:1, pp. 42-46, 1993.

30. J. W. Rhue and S. J. Lynn, Fantasy-Proneness: Developmental Antecedents, Journal of Personality, 55, pp. 121-137, 1987.

31. J. W. Rhue, S. J. Lynn, S. Henry, K. Buhk, and P. Boyd, Child Abuse, Imagination and Hypnotizability, Imagination, Cognition and Personality, 10:1, pp. 53-63, 1990-1991.

32. H. Nagera, The Imaginary Companion: Its Significance for Ego Development and Conflict Resolution, Psychoanalytic Study of the Child, 24, pp. 165-169, 1969.

33. B. Sanders, The Imaginary Companion Experience in Multiple Personality Disorder, Dissociation, 5:3, pp. 160-163, 1992.

34. L. C. Dierker, F. D. Davies, and B. Sanders, The Imaginary Companion: An Analysis of Personality Correlates and Developmental Antecedents, Dissociation, 8:4, pp. 220-228, 1995. 
35. J. H. Hilgard, Imaginative Involvement: Some Characteristics of the Highly Hypnotizable and Nonhypnotizable, International Journal of Clinical and Experimental Hypnosis, 22, pp. 238-256, 1974.

36. V. E. Pollock, J. Briere, L. Schneider, J. Knop, S. A. Mednick, and D. W. Goodwin, Childhood Antecedents of Antisocial Behavior: Parental Alcoholism and Physical Abusiveness, American Journal of Psychiatry, 147, pp. 1290-1293, 1990.

37. C. Stukas-Davis, The Influence of Childhood Sexual Abuse and Male Sex Role Socialization on Adult Sexual Functioning, unpublished doctoral dissertation, California School of Professional Psychology, Los Angeles, 1990.

38. E. B. Hurlock and M. Burstein, The Imaginary Playmate: A Questionnaire Study, Journal of Genetic Psychology, 41, pp. 380-392, 1932.

39. M. Svendson, Children's Imaginary Companions, Archives of Neurology and Psychiatry, 32, pp. 985-999, 1934.

40. E. L. Bliss, Multiple Personality, Allied Disorders, and Hypnosis, Oxford University Press, New York, 1989.

41. G. Adler, Borderline Psychopathology and Its Treatment, Aronson, New York, 1985.

42. M. M. Linehan, Cognitive-Behavioral Treatment of Borderline Personality Disorder, Guilford, New York, 1993.

43. J. M. G. Williams, Autobiographical Memory and Emotional Disorders, in Handbook of Emotion and Memory, S. A. Christianson (ed.), Erlbaum, Hillsdale, New Jersey, 1991.

44. K. Kemp, A. D. Gilbertson, and M. Torem, The Differential Diagnosis of Multiple Personality Disorder from Borderline Personality Disorder, Dissociation, 1:4, pp. 41-46, 1988.

45. F. W. Putnam, Diagnosis and Treatment of Multiple Personality Disorder, Guilford, New York, 1989.

46. M. H. Stone, Psychiatrically Ill Relatives of Borderline Patients: A Family Study, Psychiatric Quarterly, 58, pp. 71-83, 1981.

47. J. B. Bryer, B. A. Nelson, J. B. Miller, and P. A. Kroll, Childhood Sexual Abuse and Physical Abuse as Factors in Adult Psychiatric Illness, American Journal of Psychiatry, 144, pp. 1426-1430, 1987.

48. J. Lauer, D. W. Black, and P. Keen, Multiple Personality Disorder and Borderline Personality Disorder: Distinct Entities or Variations on a Common Theme? Annals of Clinical Psychiatry, 5, pp. 129-134, 1993.

49. S. Boon and N. Drajer, The Differentiation of Patients with MPD or DDNOS from Patients with Cluster B Personality Disorder, Dissociation, 6, pp. 126-135, 1993.

50. American Psychiatric Association, Diagnostic and Statistical Manual for Mental Disorders (4th ed.), Washinton, DC, p. 654, 1994.

51. T. M. Pokrajac, Dissociative Experiences in Multiple Personality and Borderline Personality, doctoral dissertation, Pepperdine University, 1994.

52. S. S. Marmer and D. Fink, Rethinking the Comparison of Borderline Personality Disorder and Multiple Personality Disorder, Psychiatric Clinics of North America, 17:4, pp. 743-771, 1994.

53. J. Armstrong and R. Loewenstein, Characteristics of Patients with Multiple Personality and Dissociative Disorders on Psychological Testing, Journal of Nervous and Mental Disease, 178, pp. 448-458, 1990. 
54. F. Leavitt and S. M. Labott, Rorschach Indicators of Dissociative Identity Disorders: Clinical Utility and Theoretical Implications, Journal of Clinical Psychology, 54:6, pp. 803-810, 1998.

55. B. G. Braun and E. J. Frischoltz, Remembering and Forgetting in Patients Suffering from Multiple Personality Disorder, in The Handbook of Emotion and Memory: Research and Theory, S. Christianson (ed.), Lawrence Erlbaum, Hillsdale, New Jersey, pp. 411-427, 1992.

56. M. T. Orne and B. L. Bates, Reflections on Multiple Personality Disorder: A View from the Looking-Glass of Hypnosis Past, in The Mosaic of Contemporary Psychiatry in Perspective, C. Pierce, M. Greeblatt, and A. Kales (eds.), Springer-Verlag, New York, 1992.

57. R. Ofshe and E. Waters, Making Monsters: False Memories, Psychotherapy, and Sexual Hysteria, Charles Scribner's Sons, New York, 1994.

58. N. P. Spanos, Multiple Identities \& False Memories: A Sociocognitive Perspective, American Psychological Association, Washington, D.C., 1996.

59. R. L. Lowenstein and D. R. Ross, Multiple Personality and Psychoanalysis: An Introduction, Psychoanalytic Inquiry, 12:1, pp. 3-48, 1992.

60. R. P. Kluft, Multiple Personality Disorder: A Study of 22 Cases, Psychiatric Clinics of North America, 7, pp. 9-29, 1984.

61. R. P. Kluft, Personality Unification in Multiple Personality Disorder: A Follow-Up Study, in Treatment of Multiple Personality Disorder, B. G. Braun (ed.), American Psychiatric Press, Washington, D.C., pp. 29-60, 1986.

62. R. P. Kluft, Clinical Approaches to the Integration of Personalities, in Clinical Perspectives on Multiple Personality Disorder, R. P. Kluft and C. G. Fine (eds.), American Psychiatric Press, Washington, D.C., pp. 101-133, 1993.

63. R. A. Goulding and R. C. Schwartz, The Mosaic Mind: Empowering the Tormented Selves of Child Abuse Survivors, W. W. Norton, New York, 1995.

64. M. Phillips and C. Frederick, Healing the Divided Self: Clinical and Ericksonian Hypnotherapy for Post-Traumatic and Dissociative Conditions, W. W. Norton, New York, 1995.

65. H. J. M. Hermans, Voicing the Self: From Information Processing to Dialogical Interchange, Psychological Bulletin, 119, pp. 31-50, 1996.

66. J. G. Watkins and H. H. Watkins, Ego States: Theory and Therapy, W. W. Norton, New York, 1997.

Direct reprint requests to:

Eli Somer, Ph.D.

School of Social Work

University of Haifa

Mt. Carmel, Haifa 31905

Haifa, Israel

e-mail: somer@research.haifa.ac.il 